\section{THU0381 PATIENT-REPORTED IMPACT OF AXIAL SPONDYLOARTHRITIS ON WORKING LIFE: RESULTS FROM THE EMAS SURVEY}

Marco Garrido-Cumbrera ${ }^{1,2}$, Laure Gossec ${ }^{3,4}$, Victoria Navarro-Compán ${ }^{5}$, David Gálvez-Ruiz ${ }^{1}$, Christine Bundy ${ }^{6}$, Raj Mahapatra ${ }^{7}$, Souzi Makri ${ }^{8}$, Sergio SanzGómez ${ }^{1}$, Carlos Delgado Domínguez ${ }^{1}$, Denis Poddubnyy ${ }^{9,10}$, EMAS Working Group. 'Universidad de Sevilla, Health and Territory Research (HTR), Seville, Spain; ${ }^{2} C E A D E$, Madrid, Spain; ${ }^{3}$ Sorbonne Université, Paris, France $;{ }^{4}$ Pitié Salpêtrière Hospital, AP-HP, Rheumatology Department, Paris, France; ${ }^{5} \mathrm{Hospital}$ Universitario La Paz, IdiPaz, Madrid, Spain; ${ }^{6}$ Cardiff University, Cardiff, United Kingdom; ${ }^{7}$ Ankylosing Spondylitis International Federation (ASIF), London, United Kingdom; ${ }^{8}$ Cyprus League Against Rheumatism, Nicosia, Spain; ${ }^{9}$ CharitéUniversitätsmedizin Berlin, Berlin, Germany, ${ }^{10}$ German Rheumatism Research Centre, Berlin, Germany

Background: Axial spondyloarthritis (axSpA) impacts multiple dimensions of patients' lives, including working life.

Objectives: To evaluate work-related issues, their associations and determinants among European axSpA patients.

Methods: The European Map of Axial Spondyloarthritis (EMAS), conducted from July 2017 to February 2018, was a cross-sectional on-line survey of unselected patients with self-reported axSpA from Austria, Belgium, France, Germany, Italy, Netherlands, Norway, Russia, Slovenia, Spain, Sweden, Switzerland, and the UK. Participants were recruited through an on-line panel and patient organizations. Participants were classified as active (employed, unemployed between 15-64 years) or inactive (retirees, on sick leave, students and homemakers). Those employed were asked to report work-related issues (sick-leave, difficulty fulfilling work hours, missing work for doctors' appointments, reducing working hours or taking days off) in the past 12 months. Disease activity (BASDAI), self-reported spinal stiffness, diagnostic delay and psychological distress (General Health Questionnaire, GHQ-12) were compared between employed patients with or without work-related issues using a Mann-Whitney and Kruskal-Wallis test. Two-stage regression analysis was conducted to determine explicative sociodemographic (using stepwise method for income, age, gender, education) and disease-related factors (enter method for BASDAI, self-reported spinal stiffness, functional limitation) over workrelated issues.

Results: 2846 axSpA patients participated in EMAS: mean age was 44 \pm 12 years, $61.3 \%$ were female and $48.1 \%$ were university educated.

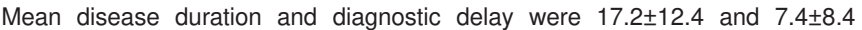
years, respectively, and mean BASDAI was 5.5 \pm 2.0 . 61.3\% ( $n=1653)$ were considered active, of which $87.7 \% \quad(n=1450)$ were employed. Of those employed, $67.7 \%$ reported a work-related issue, specifically $56.3 \%$ took sick leave, $44.6 \%$ had difficulties in fulfilling the working hours, $34.6 \%$ missed work due to doctor's appointments, $31.6 \%$ requested days off, and $25.7 \%$ reduced their number of working hours (Table 1). Among all patients, $74.1 \%$ faced or believed they would face difficulties finding a job due to axSpA. Experiencing work-related issues due to axSpA was significantly associated with higher disease activity, self-reported spinal stiffness, longer diagnostic delay, and higher level of psychological distress $(\mathrm{p}<0.001)$. First regression step showed gender and educational level as explanatory sociodemographic control factors, while educational level and BASDAI were the only statistically significant explanatory factors in the second step $(\mathrm{p} \leq 0.001)$ (Table 2).

Abstract THU0381 -Table 1.

Table 1. Statistical correlations between the work-related issues of employed and sociodemographic and clinical characteristics, (n:1422, unless other specified)

\begin{tabular}{|c|c|c|c|}
\hline & $\begin{array}{c}\begin{array}{c}\text { Work-related } \\
\text { issues }\end{array} \\
\text { (mean } \pm \text { SD or \%) }\end{array}$ & $\begin{array}{c}\text { No work-related } \\
\text { issues }\end{array}$ & p-value \\
\hline Age (years) & $41.4 \pm 9.7$ & $42.3 \pm 10.4$ & 0.09 \\
\hline Gender (Male) & $37.9 \%$ & $47.9 \%$ & $<0.001^{*}$ \\
\hline Education level (University) & $60.7 \%$ & $56.6 \%$ & $0.002^{*}$ \\
\hline Marital status (Married) & $67.5 \%$ & $69.3 \%$ & 0.06 \\
\hline $\operatorname{BASDAI}(0-10), \mathrm{n}: 1310$ & $5.4 \pm 1.8$ & $4.0 \pm 2.0$ & $<0.001^{*}$ \\
\hline $\operatorname{BASDAI}(\geq 4), n: 1,310$ & $79.0 \%$ & $50.2 \%$ & $<0.001^{*}$ \\
\hline Stiffness index (3-12) & $7.5 \pm 2.4$ & $6.3 \pm 2.5$ & $<0.001^{*}$ \\
\hline GHQ-12 (0-12), n:1,344 & $5.1 \pm 4.0$ & $2.6 \pm 3.2$ & $<0.001^{*}$ \\
\hline GHQ-12 ( $\geq 3), n: 1,344$ & $64.6 \%$ & $34.1 \%$ & $<0.001^{*}$ \\
\hline Depression, n:1,371 & $26.1 \%$ & $11.1 \%$ & $<0.001^{*}$ \\
\hline Anxiety, $\mathrm{n}: 1,368$ & $32.2 \%$ & $16.1 \%$ & $<0.001^{*}$ \\
\hline
\end{tabular}

${ }^{*}$ Test $x^{2}$ and Mann-Whitney to indicate if there is an association between the variables.
Abstract THU0381 -Table 2

Table 2. Regression analysis on the determinants of the presence of work-related issues of patients with axSpA and their demographic, socioeconomic and disease-related parameters. $n=1162$.

\begin{tabular}{|c|c|c|c|c|c|}
\hline & Sig. of change in & Second stage & Sig. of & \multicolumn{2}{|c|}{ Goodness of fit statistics } \\
\hline Income & 0.568 & NA & & \multirow[t]{2}{*}{ Cox-Snell $R^{2}$} & \multirow[t]{2}{*}{234} \\
\hline Age & 0.443 & $\mathrm{NA}$ & & & \\
\hline Gender & 0.009 & ,052 & 691 & \multirow[t]{2}{*}{ Nagelkerke $R^{2}$} & \multirow[t]{2}{*}{312} \\
\hline Education level & 0.033 & 160 & 016 & & \\
\hline Stiffness Index & NA &,- 032 & 271 & \multirow{3}{*}{$\begin{array}{l}\text { Percentage of } \\
\text { correct } \\
\text { predictions }\end{array}$} & \multirow[t]{3}{*}{$72 \%$} \\
\hline Limitation Index & NA & 001 & 891 & & \\
\hline BASDAI & NA & -284 & .000 & & \\
\hline
\end{tabular}

Conclusion: Nearly two-thirds of employed patients experienced workrelated issues due to axSpA. The strongest factor associated with workrelated issues was high disease activity. Understanding the determinants of work-related issues is needed to ensure that patients have adequate workplace and holistic medical support to lead productive work-lives Acknowledgement: EMAS was funded by Novartis Pharma AG

Disclosure of Interests: Marco Garrido-Cumbrera Consultant for: Honoraria from Novartis as steering committe of this survey, Laure Gossec Grant research support from: AbbVie, BMS, Celgene, Janssen, Lilly, MSD Novartis-Sandoz, Pfizer, Sanofi, and UCB, Consultant for: AbbVie, Biogen, BMS, Celgene, Janssen, Lilly, MSD, Nordic Pharma, Novartis-Sandoz, Pfizer, Roche, Sanofi, and UCB, Consultant for: L Gossec has received honoraria from Celgene as investigator for this study, Victoria NavarroCompán: None declared, David Gálvez-Ruiz Consultant for: Honoraria from Novartis as steering committe of this survey, Christine Bundy Consultant for: Honoraria from Novartis as steering committe of this survey, Raj Mahapatra Consultant for: Honoraria from Novartis as steering com mitte of this survey, Souzi Makri: None declared, Sergio Sanz-Gómez: None declared, Carlos Delgado Domínguez Consultant for: Honoraria from Novartis as steering committe of this survey, Denis Poddubnyy Grant/ research support from: AbbVie, Merck Sharp \& Dohme, Novartis, Consultant for: AbbVie, Bristol-Myers Squibb, Janssen, Merck Sharp \& Dohme, Novartis, Pfizer, UCB Pharma, Speakers bureau: AbbVie, Bristol-Myers Squibb, Janssen, Merck Sharp \& Dohme, Novartis, Pfizer, Roche, UCB Pharma

DOI: 10.1136/annrheumdis-2019-eular.7054

\section{THU0382 FACTORS ASSOCIATED WITH POOR WORK OUTCOMES IN PATIENTS WITH AXIAL SPONDYLOARTHRITIS IN SINGAPORE}

Yihui Goh ${ }^{1,2}$, Yu Heng Kwan ${ }^{3}$, Ying Ying Leung ${ }^{1}$, Warren Fong ${ }^{1,4,5}$, Peter Cheung ${ }^{2} .{ }^{1}$ Department of Rheumatology and Immunology, Singapore General Hospital, Singapore, Singapore; ${ }^{2}$ Division of Rheumatology, National University Hospital, Singapore, Singapore; ${ }^{3}$ Program in Health Services and Systems Research, Duke-NUS Medical School, Singapore, Singapore; ${ }^{4}$ DukeNUS Medical School, Singapore, Singapore; ${ }^{5}$ Department of Medicine, Yong Loo Lin School of Medicine, National University of Singapore, Singapore, Singapore

Background: Axial spondyloarthritis (axSpA) can lead to significant limitation of mobility and function, resulting in poor work outcomes. ${ }^{1}$ Factors associated with poor work outcomes have not been studied in an Asian population. Singapore is an urban Asian city with a low unemployment rate and a healthcare model with heavy emphasis on self-reliance. ${ }^{2}$ This socio-cultural context may influence risk factors for poor work outcomes.

Objectives: To identify factors associated with poor work outcomes in patients with axSpA in Singapore.

Methods: A cross-sectional study was performed in two tertiary centres in Singapore. Patients $\geq 21$ years fulfilling Assessment in Spondyloarthritis International Society (ASAS) 2009 criteria for axSpA were included. We collected social demographics, clinical data, treatment modalities and patient reported outcomes, including the Bath Ankylosing Spondylitis Disease Activity Index (BASDAI), Bath Ankylosing Spondylitis Functional Index (BASFI), EQ-5D index, and Work Productivity and Activity Impairment scale (WPAI:SpA). WPAI:SpA was used to derive scores for presenteeism (reduced productivity while at work), absenteeism (time absent from work), work impairment (combining presenteeism and absenteeism scores) and activity impairment (impairment in activities performed outside of work). Univariable and multivariable linear regressions were used to 
examine factors associated with presenteeism, absenteeism, work impairment and activity impairment.

Results: A total of 156 patients with axSpA were included: $72.4 \%$ employed, $80.1 \%$ male, $86.5 \%$ Chinese, mean age 39.2 (13.0) years, mean disease duration 8.5 (8.9) years. The mean BASDAI was $3.2(2.0)$, mean BASFI was 2.1 (2.1), mean EQ-5D was $0.8(0.1)$ and mean activity impairment was $28.2 \%$. Among employed patients, mean absenteeism was $4.5 \%$, mean presenteeism was $24.9 \%$ and mean work impairment was $27.6 \%$. In multivariable analysis, absenteeism was associated with disease duration (B: $-0.44 ; 95 \% \mathrm{Cl}:-0.80,-0.07 ; p=0.02$ ) and $E Q-5 D$ (B: 46.28; 95\% Cl: -89.63, -2.92; $\mathrm{p}=0.04)$. Presenteeism was associated with $B A S D A I \geq 4$ (B: $8.23 ; 95 \% \quad C l: 0.24,16.22 ; p=0.04)$, BASFI (B: $3.59 ; 95 \%$ Cl: 1.25, 5.92; $p<0.01$ ) and EQ-5D (B: -64.40; 95\% Cl: $-115.79,-13.02$; $\mathrm{p}=0.02)$. Work impairment was associated with BASFI (B: $3.57 ; 95 \% \mathrm{Cl}$ : $0.71,6.43 ; \mathrm{p}=0.02$ ) and $\mathrm{EQ}-5 \mathrm{D}$ (B: $-88.00,95 \% \mathrm{Cl}:-150.87,-25.13$; $\mathrm{p}<0.01)$. Activity impairment was associated with age $(B:-0.21 ; 95 \% \mathrm{Cl}$ : $0.41, \quad-0.01 ; \quad p=0.04), \quad B A S D A I \geq 4 \quad$ (B: 19.94; $95 \% \quad C l: 13.79,26.09 ;$ $p<0.01$ ), BASFI (B: 3.29; 95\% Cl: 1.63, 4.95; $p<0.01$ ), EQ-5D (B: -82.28 ; 95\% Cl: $-125.15,-39.41 ; p<0.01)$.

Conclusion: Factors such as active disease, reduced physical function and poorer quality of life are associated with reduced work outcomes in patients with axSpA in Singapore. These factors need to be addressed to improve work outcomes.

\section{REFERENCES}

[1] Martindale, J., et al. (2015). "The impact of ankylosing spondylitis/axial spondyloarthritis on work productivity." Best Pract Res Clin Rheumatol 29 (3): 512-523

[2] $\mathrm{Ng}$, I. Y., et al. (2012). "Designing and implementing an evaluation of a national work support program." Eval Program Plann 35(1): 78-87

Disclosure of Interests: Yihui Goh: None declared, Yu Heng Kwan: None declared, Ying Ying Leung Grant/research support from: Abbvie, Novartis Speakers bureau: Abbvie and Novartis, Speakers bureau: Novartis, Warren Fong : None declared, Peter Cheung: None declared DOI: 10.1136/annrheumdis-2019-eular.4143

\section{THU0383 PREVALENCE OF SPONDYLOARTHRITIS IN FIRST DEGREE RELATIVES OF PATIENTS WITH ANKYLOSING SPONDYLITIS}

Monika Gregová ${ }^{1}$, Kristyna Bubova ${ }^{1}$, Kateřina Zegzulková ${ }^{,}$, Karel Pavelka ${ }^{1}$, Ladislav Šenolt ${ }^{1} .{ }^{1}$ Institute of Rheumatology, Department of Rheumatology, Prague, Czech Republic; ${ }^{2}$ Institue of Rheumatology, Department of Rheumatology, Prague, Czech Republic

Background: Ankylosing spondylitis (AS) is a common rheumatic disease with higher prevalence in relatives of patients already diagnosed with the disease. Heritability of AS in twins is estimated to $90 \%$.

Objectives: The aim of this study was to examine first degree relatives (FDR) of AS patients, to determine whether the patients already fulfil criteria for axial and/or peripheral spondyloarthritis $(\mathrm{SpA})$ and compare the findings to healthy controls $(\mathrm{HC})$.

Methods: We recruited 32 patients without prior rheumatologic diagnosis with first degree relative treated for AS and 20 age and sex matched $\mathrm{HC}$. The clinical data were collected and rheumatology examinations were performed by trained rheumatologists. Magnetic resonance imaging (MRI) of sacroiliac joints (SIJ) was read by trained rheumatologist who was blinded to the patient's data. Patients were further divided into the subsets of axial SpA (imaging and clinical arm) and peripheral SpA fulfilling The Assessment of SpondyloArthritis international Society (ASAS) classification criteria $^{1}$ and subset of non-SpA. The ASAS modified Berlin algorithm for diagnosis of axial $\mathrm{SpA}^{2}$ (axSpA) was also applied.

Results: Altogether, 78\% ( $n=25)$ FDR referred back pain, 34\% ( $n=11)$ referred inflammatory back pain (IBP), and $22 \%(n=7)$ did not refer back pain, which was significantly different from that in $\mathrm{HC}(65 \%$ referred back pain, $0 \%$ referred IBP, 35\% referred no back pain, $p=0.0038$ and $p=0.03$, respectively). Bone marrow edema (BME) was found in $50 \% \quad(n=16)$ of FDR, and $22 \%(n=7)$ had highly suggestive $B^{3} E^{3}$ (hsBME) corresponding to typical findings of active sacroiliitis compared to $\mathrm{HC}$ where $10 \%(\mathrm{n}=2)$ had $B M E$, and none had $\operatorname{hsBME}(p=0.063, p=0.035$, respectively). Furthermore, FDR had higher BASDAI and higher prevalence of HLA-B27 positivity compared to $\mathrm{HC}(2.0( \pm 1.5)$ and $75 \%$ vs. $0.4( \pm 0.6)$ and $5 \%$, $\mathrm{p}=0.001$ and $\mathrm{p}=0.001$, respectively), no other significant differences were observed. The diagnosis of $\mathrm{SpA}$ was confirmed in $37 \% \quad(n=12)$ of all FDR, 25\% $(n=8)$ patients fulfilled the imaging arm and $6 \%(n=2)$ fulfilled the clinical arm of ASAS classification criteria for $\operatorname{axSpA}, 6 \% \quad(n=2)$ patients fulfilled ASAS classification criteria for peripheral SpA. The diagnosis of axSpA according to the ASAS modified Berlin algorithm was confirmed in $41 \% \quad(n=13)$ patients. Analysis of clinical characteristics showed significant difference between serum CRP levels in SpA vs. nonSpA $(8.2( \pm 12.5)$ vs. $2.3( \pm 4.4), p=0.02$, respectively) and HLA-B27 positivity $(100 \%$ vs. $60 \%, p=0.01$, respectively). Presence of back pain and inflammatory back pain were more often in SpA compared to non-SpA subsets $(100 \%$ and $67 \%$ vs. $65 \%$ and $15 \%, p=0.03$ and $p=0.006$, respectively)

Conclusion: More than one third of first degree relatives of patients with AS fulfilled the criteria for axial or peripheral $\mathrm{SpA}$, and had significantly higher prevalence of inflammatory back pain and increased BASDAI com pered to $\mathrm{HC}$. Based on these data, screening of family members of patients with AS should be recommended.

\section{REFERENCES:}

[1] Rudwaleit M, van der Heijde D, Landewé R, et al. The development of Assessment of SpondyloArthritis international Society classification criteria for axial spondyloarthritis (part II): validization and final selection. Ann Rheum Dis 2009; 68: 777-83.

[2] van der Berg R, de Hooge $M$, Rudwaleit $M$, et al. ASAS modification of the Berlin algorithm for diagnosing axial spondyloarthritis: results from the SPondyloArthritis Caught Early (SPACE)-cohort and from the Assessment of SpondyloArthritis international Society (ASAS)-cohort. Ann Rheum Dis 2013; 72: 1646-53.

[3] Lambert RG, Bakker PA, van der Heijde D, et al. Defining active sacroiliitis on MRI for classification of axial spondyloarthritis: update by the ASAS MRI working group. Ann Rheum Dis 2016; 75: 1958-68.

Acknowledgement: Supported by MH CR 023728, SVV 260373, AZV - 1733127A

Disclosure of Interests: Monika Gregová: None declared, Kristyna Bubova: None declared, Kateřina Zegzulková: None declared, Karel Pavelka: None declared, Ladislav Šenolt Grant/research support from: AbbVie, Consultan for: AbbVie, Bristol-Myers Squibb, Celgene Corporation, Merck Sharp and Dohme, Novartis, Pfizer, Roche, UCB, Amgen, Takeda, Speakers bureau: AbbVie, Amgen, Bristol-Myers Squibb, Celgene Corporation, Eli Lilly, Merck Sharp and Dohme, Novartis, Pfizer, Roche, UCB DOI: 10.1136/annrheumdis-2019-eular.7779

\section{THU0384 IMAGING OF SACROILIAC JOINTS IN EARLY SPONDYLOARTHRITIS: SHOULD WE CHOOSE COMPUTED TOMOGRAPHY OR MAGNETIC RESONANCE IMAGING?}

Wafa Hamdi ${ }^{1}$, Dorra Ben Nessib ${ }^{1}$, Dhia Kaffel ${ }^{1}$, Kaouther Maatallah $^{1}$, Hanene Ferjani ${ }^{1}$, Hend Riahi ${ }^{2}$, Med Montacer Kchir ${ }^{1} .{ }^{1}$ Kassab Institute, Rheumatology, Manouba, Tunisia; ${ }^{2}$ Kassab Institute, Radiology, Manouba, Tunisia

Background: In view of the limited utility of pelvic radiography to recog nize sacroiliitis in its earliest stages, magnetic resonance imaging (MRI) has been considered as a reliable imaging modality to detect acute subchondral inflammation at disease onset. However, several recent studies reported a high proportion of false-positive of sacroiliac joints (SIJ) MRI Other studies demonstrated that computed tomography (CT), by its ability to detect early structural damage, may be helpful. Consequently, strengths and limitations of each imaging technique need to be considered when choosing the most appropriate first-line modality in clinical practice.

Objectives: We aimed to assess the performance of CT scanning and MRI for detecting sacroiliitis in early SpA by estimating the sensitivity and the specificity of each imaging technique.

Methods: Consecutive patients, aged 16 years and over, referred for symptoms suggestive of SpA from February 2014 to February 2017 were enrolled in this cohort. After excluding patients whose conventional radiog raphy showed a confirmed sacroiliitis, eligible patients underwent SIJ CT and/or MRI. The CT and MR images were reviewed by 2 musculoskeletal radiologists blinded to clinical findings. Then, 2 rheumatologists recorded from the clinical files if patients fulfilled the ASAS (Assessment of Spondyloarthritis international Society) classification criteria for SpA. This classification was considered as the gold standard of this study. Results: Fifty-three patients were included: 14 men and 39 women. The mean age was 36 years. The prevalences of HLA-B27 and elevated CRP were $27.6 \%$ and $16 \%$, respectively. Fifty-eight percent of the patients $(n=31)$ fulfilled the ASAS criteria for axial SpA. Among these patients, 30 patients underwent SIJ CT and 27 underwent SIJ MRI. Sac roiliitis was visualized by CT in 28 out of 30 patients $(93.3 \%$ ) and by MRI in 17 out of 27 patients (63\%). Among the 22 patients who did not 